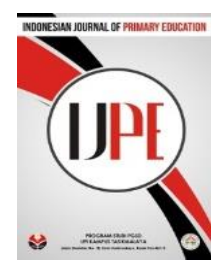

Vol. 2, No. 2 (2018) 40-47 ISSN: 2597-4866

Indonesian Journal of Primary Education

\title{
Pembelajaran Stem Berbasis Outbound Permainan Tradisional
}

\author{
Irman Artobatama \\ Universitas Pendidikan Indonesia Kampus Tasikmalaya \\ *Corresponding author: irman.artobatama@gmail.com \\ Diterima 20 Agustus 2018; Direview 18 September 2018; Diterima 15 Oktober 2018 \\ Diterbitkan online 28 Desember 2018
}

\begin{abstract}
Learners is one of the essential elements in the process of education, educators must continually educate learners as needed. The developed countries like America had developed appropriate learning community needs i.e. learning-based technology. Learning in Indonesia pun there needs to be innovation for learning at this time. Learning in school need to have linkages with technology so that learning can be applied in the community. Learning at school any need to incorporate cultural elements so that learners have a high national soul. The study about learning that combines science, technology, math, simple machine with the game trasional, the trail can be applied outdoors. The blend of learning STEM (Saintific, Technology, Engineering and Mathematics) with the traditional game-based Outbound learning applied in the Pool becomes a solution to develop effective learning. STEM-based learning with learning the traditional game-based Outbound implemented in pool in tune with the times already technology-based and globally. This learning can progress rapidly if implemented in schools especially in elementary school. Thus the combination of the learning-based STEM Learning with traditional game-based Outbound applied to the Pool used in elementary school. Because in this learning in every teaching and learning meetings will result in a product or work of learners. It can be concluded that this study combines STEM, traditional games, the outbound as well as outdoors.
\end{abstract}

Keywords: STEM; Traditional Games; the Outbound.

\begin{abstract}
Abstrak
Peserta didik merupakan salah satu unsur penting dalam proses pendidikan. Pendidik harus senantiasa mendidik sesuai keperluan peserta didik. Pendidikan negara-negara maju di dunia seperti Amerika sudah mengembangkan pembelajaran sesuai kebutuhan masyarakat yakni pembelajaran berbasis teknologi. Pembelajaran di Indonesia pun perlu ada inovasi untuk pembelajaran saat ini agar Indonesia dapat menyesuaikan dengan keadaan zaman dan tidak tertinggal. Pembelajaran di sekolah perlu ada kaitannya dengan tekonologi yang relevan, agar pembelajaran dapat diterapkan di masyarakat. Pembelajaran di sekolah pun perlu memasukan unsur budaya supaya peserta didik memiliki jiwa nasional yang tinggi. Pengkajian tentang pembelajaran yang memadukan sains, teknologi, mesin sederhana, matematika dengan permainan trasional, penjelajahan yang dapat diterapkan di luar ruangan. Perpaduan pembelajaran STEM (Saintific, Technology, Engineering and Mathematics) dengan pembelajaran Outbond berbasis permainan tradisional yang diterapkan di outdoor menjadi suatu solusi untuk mengembangkan pembelajaran efektif. Pembelajaran STEM berbasis outbound permainan tradisional yang diimplementasikan di luar ruangan selaras dengan perkembangan zaman yang sudah berbasis teknologi dan global. Pembelajaran ini dapat berkembang dengan pesat apabila diimplementasikan di sekolah terutama di Sekolah Dasar. Dengan demikian Pembelajaran STEM berbasis Outbound Permainan Tradisional yang diterapkan di outdoor tepat digunakan di Sekolah Dasar. Karena di pembelajaran ini di setiap pertemuan belajar, mengajar akan menghasilkan produk atau karya dari peserta didik. Dapat disimpulkan bahwa pembelajaran ini menggabungkan STEM, outbond, dan permainan tradisional.
\end{abstract}

Kata Kunci: STEM; Permainan Tradisional; Outbond.

\section{PENDAHULUAN}

Pendidikan Indonesia diharapkan selalu meningkat setiap tahunnya. Indonesia akan mencapai Generasi Emas di tahun 2025. Sementara Pembelajaran formal di Indonesia peningkatannya belum begitu signifikan. Bila melihat pendidikan negara maju, sebut saja Amerika yang pendidikannya di atas kita terdapat pembelajaran yang sudah dimodifikasi agar pendidikan dapat 
menungkat secara optimal. Dan di Amerika menggunakan pembelajaran berbasis STEM. Indonesia pun mampu untuk meningkatkan pendidikannya, salah satunya dengan menggunakan pembelajaran berbasis STEM yang harus ada modifikasi yang menciri-khaskan Indonesia dibanding negara lain.

Menurut Permananasari (2016, hlm 1) mengatakan bahwa STEM education merupakan inovasi pembelajaran yang memadukan sains, matematika untuk dapat berfikir logis dan rasional, sehingga dapat memahami fenomena secara logis, dan kritis.

Ciri khas di negara Indonesia adalah kaya akan budaya dan keaneka ragaman, itu dapat dimanfaatkan untuk kemajuan pendidikan melalui pembelajaran yang dikaitkan dengan permainan tradisional. Munculah ide untuk memadukan antara pembelajaran berbasis stem dengan pembelajaran outbond berbasis permainan tradisional yang dapat diterapkan di luar ruangan.

Menurut Setyowati,I (2011, hlm 1) menyatakan bahwa kegiatan belajar mengajar harus dapat membekali peserta didik dengan kecakapan hidup (life skill) yang sesuai dengan lingkungan kehidupan dan kebutuhan peserta didik. Memang karena sesuai dengan Kurikulum 2013 bahwa peserta didik dituntut tidak hanya kognitifnya saja tapi juga afektif dan psikomornya. Sehingga terdapat paduan antara sikap, kecerdasan dan keterampilan. Dengan adanya pembelajaran berbasis STEM yang dipadukan dengan pembelajaran outbond berbasis permainan tradisional yang dapat diimplementasikan di luar ruangan.

"Prinsip utama perkembangan dasar peserta didik yaitu koordinasi gerak motorik kasar maupun halus dengan ada interaksi sesama individu" (Wulandari, Y, 2013, hlm 2). Karena di pembelajaran permainan tradisional terdapat nilai budaya dan cinta tanah air sebagai generasi penerus bangsa yang diharapkan mampu membangun dan mengembangkan Indonesia.

\section{KAJIAN PUSTAKA}

Dalam suatu Artikel diperlukan dukungan hasil-hasil penelitian yang telah ada sebelumnya yang berkaitan Pembelajaran STEM, Outbond, Outdoor dan Permainan Tradisional. Menurut Permananasari (2016, hlm 1) mengatakan bahwa STEM education merupakan inovasi pembelajaran yang memadukan sains, matematika untuk dapat berfikir logis dan rasional, sehingga dapat memahami fenomena secara logis, dan kritis. Sedangkan menurut Setyowati,I (2011, hlm 1) menyatakan bahwa kegiatan belajar mengajar harus dapat membekali peserta didik dengan kecakapan hidup (life skill) yang sesuai dengan lingkungan kehidupan dan kebutuhan peserta didik. "Prinsip utama perkembangan dasar peserta didik yaitu koordinasi gerak motoric kasar maupun halus dengan ada interaksi sesama individu"(Wulandari, Y, 2013, hlm 2). Menurut Utami, IS(2017, hlm,6) pembelajaran STEM dapat meningkatkan pemahaman konsep, karena dapat secara langsung mengaitkan konsep 
fisika dan ketika diberikan lembar kerja berbasis STEM, siswa antuasias dalam mengerjakan. "Dengan pembelajaran STEM, mahasiswa dapat melakukan penyelidikan untuk memecahkan masalah di Sekolah Dasar, serta pemahaman konsep materi lebih lengkap diterima siswa dalam belajar"(Utami, IS, 2017, hlm.7)

Begitu pun menurut Nailul Falah (2014, hlm. 4), menyatakan bahwa efektifitas merujuk pada kemampuan untuk memeiliki tujuan yang tepat atau mencapai tujuan yang telah ditetapkan. "Metode pembelajaran merupakan sebuah mediator yang mengolah dan mengembangkan suatu gagasan sehingga menghasilkan suatu teori atau temuan untuk menyampaikan sebuah visi pembelajaran kepada tujuannya"(Falah, N.2018. hlm.8)

Menurut Nailul Falah (2014, hlm. 4), menyatakan bahwa outbond adalah kegiatan di alam terbuka, outbond dapat memicu semangat belajar serta sebagai sarana penambah wawasan pengetahuan yang di dapat dari serangkaian pengalaman berpetualang memicu semangat dan kreatifitas seseorang. Melalui outbond akan berpadunya keterampilan dan kognitif yang menghasilakan pemahaman yang akan dapat dipahami secara lengkap.

Menurut Fitri F (2016, hlm.6) menjelaskan bahwa pembelajaran dengan outbond yang disajikan di media cetak atau tidak merupakan buku panduan yang dapat mengembangkan pembelajaran lebih menarik. Antusias peserta didik dalam belajar disebabkan konsep materi yang masukan kedalam penjelajahan atau pembelajaran Outbond yang terencana. Menurut Ilham (2016, hlm.4) menyatakan bahwa permainan tradisional adalah permainan yang mengandung unsur-unsur kebudayaan yang berharga, karena permainan tradisional memberikan pengaruh yang besar terhadap perkembangan kejiwaan, sifat dan kelangsungan social.

Menurut Nurdewi (2012, hlm.11) menyatakan bahwa outbond merupakan serangkaian permainan dalam program pendidikan dan pelatihan yang dilaksanakan diluar ruangan (outdoor) dengan konsep bersenang-senang sambil belajar. Dengan demikian pembelajaran outdoor ini dapat diimplementasikan melalui beberapa konsep materi yang sesuai.

"Materi, proses, dan fungsi permainan tradisional juga merupakan media yang tepat untuk belajar, karena dapat bermain dengan ceria, setelah permainan usai tanpa disadari ada pengetahuan yang didapat, juga memberikan pendidikan lingkungan sekitar serta menghormati sesame"(Subagiyo, H. hlm.6).

Dengan demikian perpaduan pembelajaran ini perlu diterpkan di Sekolah Dasar karena memiliki keterpaduan efektif. Oleh karena itu pembelajaran ini sangat dianjurkan untuk dipraktekan oleh guru. 


\section{PEMBAHASAN}

A. Penjelasan Pembelajaran Berbasis STEM

Pembelajaran STEM (Science, Techonology, Engineering and Mathematic) merupakan pembelajaran yang mengkombinasikan gtekonologi, prinsip kerja mesin atau alat dengan konsep matematika. Yang diharapkan menghasilkan karya, sehingga peserta didik khususnya Sekolah Dasar sudah dididik sejak dini tenatang perkembangan tekonologi.

Menurut Utami, IS(2017, hlm,6) pembelajaran STEM dapat meningkatkan pemahaman konsep, karena dapat secara langsung mengaitkan konsep fisika dan ketika diberikan lembar kerja berbasis STEM, siswa antuasias dalam mengerjakan. Pembelajaran tidak hanya di kelas saja, karena di usia peserta didik SD memerlukan pembelajaran yang aktif untuk mudah memahami suatu konsep. Dengan kata lain peserta didik sedang dalam tahap operasional konkrit. Tidak dapat disamakan seperti halnya oaring dewasa, akan tetapi memerlukan media dan lokasi yang memadai.

"Dengan pembelajaran STEM, mahasiswa dapat melakukan penyelidikan untuk memecahkan masalah di Sekolah Dasar, serta pemahaman konsep materi lebih lengkap diterima siswa dalam belajar"'(Utami, IS, 2017, hlm.7)
Dengan menghasilkan sebuah karya pada setiap pekan atau pertemuan, maka peserta didik akan antusias dengan pembelajaran yang terdapat pembuatan karya atau alat. Hal itu dapat mendorong peserta didik bersifat kritis dan kreatif. Karyanya pun dimulai dari yang paling sederhana, seperti membuat mobilmobilan dengan stick eskrim untuk memperkenalkan gaya pada peserta didik.

\section{B. Penjelasan Pembelajaran Berbasis Outbond}

Sebaiknya pembelajaran di sekolah terdapat pembelajaran berbasis outbond di setiap pecan, sehingga peserta didik dapat merasakan proses pembelajaran dengan berbagai tahap, melalui penjelajahan secara berkelompok yang akan menguji keberanian dan kecepatan pesrta didik dalam belajar.

Menurut Nailul Falah (2014, hlm. 4), menyatakan bahwa efektifitas merujuk pada kemampuan untuk memeiliki tujuan yang tepat atau mencapai tujuan yang telah ditetapkan.

Dengan demikian, pembelajaran ini memiliki tujuan yang menariuk yang dapat menarik minat siswa untuk berpartisipasi aktif dalam penjelajahan sambil belajar. Tanpa disadari peserta didik belajar dengan serius tanpa ada beban, dengan kata lain belajar sepenuh hati.

"Metode pembelajaran merupakan sebuah mediator yang mengolah dan 
mengembangkan suatu gagasan sehingga menghasilkan suatu teori atau temuan untuk menyampaikan sebuah visi pembelajaran kepada tujuannya"(Falah, N.2018. hlm.8)

Kemudian untuk mengoptimalkan pembelajaran dengan cara berpindah tempat dari tempat satu ke tempat lainnya membuat peserta didik mendapat suasana baru dan tidak jenuh. Artinya pembelajaran berbasis outbond memberikan keleluasaan kepada peserta didik untuk belajar dengan suasana menyenagkan dan bersosial dengan sesama.

Menurut Nailul Falah (2014, hlm. 4), menyatakan bahwa outbond adalah kegiatan di alam terbuka, outbond dapat memicu semangat belajar serta sebagai sarana penambah wawasan pengetahuan yang di dapat dari serangkaian pengalaman berpetualang memicu semangat dan kreatifitas seseorang. Melalui outbond akan berpadunya keterampilan dan kognitif yang menghasilakan pemahaman yang akan dapat dipahami secara lengkap.

"Outbond merupakan kegiatan yang di lakukan dalam rangka memperkenalkan dunia konseling kepada masyarakat dan memberikan pengalaman pelajaran yang berharga kepada murid"( Falah, N.2018. hlm.8). Dengan penjelajahan yang menambah penagalaman belajar yang berharga bagi murid dan guru.

Menurut Fitri F (2016, hlm.6) menjelaskan bahwa pembelajaran dengan outbond yang disajikan di media cetak atau tidak merupakan buku panduan yang dapat mengembangkan pembelajaran lebih menarik. Antusias peserta didik dalam belajar disebabkan konsep materi yang masukan kedalam penjelajahan atau pembelajaran Outbond yang terencana.

"Outbond merupakan program pembelajaran di luar ruangan berdasarkan prinsip pengalaman langsung yang dapat disajikan dalam bentuk permainan atau simulasi dan yang lainnya"(Fitri F. 2016, hlm 10). Oleh karena itu pembelajaran yang dipraktekan atau disimulasikan melalui pembelajaran berbasis outbond atau penjelajahan akan berhasil sesuai rencana apabila didukung peserta didik, orangtua dan guru.

\section{Penjelasan Pembelajaran Berbasis Permainan Tradisional}

Permainan tradisional sudah menjadi kekayaan ragam budaya di Negara Indonesia. Hal tersebut dimanfaatkan dalam dunia pendidikan. Salah satunya melalui pembelajaran berbasis permainan tradisional. Yang dapat memadukan beberapa mata pelajaran sesuai kurikulum. Serta diharapkan mengahasilkan sebuah proses yang realita, menjadikan peserta didik merasa nyaman untuk belajar. 
Menurut Ilham (2016, hlm.4) menyatakan bahwa permainan tradisional adalah permainan yang mengandung unsur-unsur kebudayaan yang berharga, karena permainan tradisional memberikan pengaruh yang besar terhadap perkembangan kejiwaan, sifat dan kelangsungan social. Unsur budaya dan nilai keindahan menjadi daya tarik anak, dan bagi guru menjadi solusi untuk meningkatkan pendidikan sekaligus melestarikan budaya Indonesia. Sehingga kita sebagai warga Negara Indonesia dapat berpartipsi membangun pendidikan tanpa melupakan ragam budaya atau pun pendidikan sebelumnya.

"Pemanfaatan permainan tradisional dalam upaya pencapaian indicator pembelajaran harus dirancang sedemikian rupa sehingga sesuai dengan materi pembelajaran"(Ilham. 2016, hlm.9). Materi yang disampaikan melalui permainan tradisional dapat menjadi efektif setelah guru dapat mengkondisikan sesuai jangka waktu dan materi yang ditentukan.

Menurut Ja'far (2014, hlm.3) mengatakan bahwa permainan tradisional terbentuk dari kekompakkan, interaksi antar sesama yang merupakan wujud dari kebersamaan. Pada intinya manfaat dari permainan tradisional yang digunakan untuk pembelajaran menjadi hal positif untuk menambah semangat dan cara memahami yang sederhana yakni selain menggunakan teori juga menggunakan praktek dengan bimbingan guru.

\section{Penjelasan Pembelajaran Outdoor}

Pembelajaran tidak selamanya harus indoor atau di dalam ruangan. Belajar dimana kapanpun itu dapat terjadi, termasuk di sekolah formal. Terkadang perlu mengadakan kelas di luar. Artinya pembelajaran di luar ruangan seperti belajar di pagi hari di dekat taman. Atau belajar di siang hari bertempat di bawah pohon. Itu menjadi hal unik yang perlu dikenalkan kepada siswa untuk belajar.

Menurut

Gustianana,(hlm.6) menjelaskan bahwa pembelajaran outdoor merupakan salah satu pembelajaran yang dilaksanakan agar anak-anak dapat mengetahui tempat belajar lain selain di dalam kelas, dan anak-anak akan langsung melihat dengan secara langsung yang terjadi di alam dan secara langsung berinteraksi dengan alam. Maksudnya proses pembelajaran di laksanakan outdoor dapat menambah nilai keindahan dan kenyamanan, misalkan dilaksankan setiap dua minggu sekali.

"Makna bahwa anak-anak harus mengenal lingkungannya dan juga harus bersahabat dengan lingkungannya dengan cara bermain permainan tradisional"(ja'far.2014, hlm.8). Selain siswa harus belajar membaca, menulis dan berhitung, siswa juga perlu beradaptasi 
dengan lingkungan, bersosialisasi dengan teman di alam terbuka, serta belajar dengan suasana menyenangkan. Menurut Nurdewi (2012, hlm.11) menyatakan bahwa outbond merupakan serangkaian permainan dalam program pendidikan dan pelatihan yang dilaksanakan diluar ruangan (outdoor) dengan konsep bersenang-senang sambil belajar. Dengan demikian pembelajaran outdoor ini dapat diimplementasikan melalui beberapa konsep materi yang sesuai.

"Dengan pembelajaran outbond pembelajaran menjadi lebih kreatif dalam mengelola proses pembelajaran, sedangkan peserta didik akan lebih aktif dalam kegiatan belajar sehingga memperoleh pengalaman belajar yang maksimal"(Nurdewi, hlm.30).

Oleh karena itu dalam pembelajaran permainan tradisional perlu diimplementasikan di sekolah dengan tujuan meningkatkan proses belajar optimal untuk menunjang mental, fisik dan logika anak.

\section{E. Paduan Pembelajaran Outbond Dengan Permainan Tradisional}

Pembelajaran outbond diterapkan di sekolah belum lengkap tanpa dipadukan dengan pembelajaran yang berbasis permainan tradisional. Karena dari kedua jenis pembelajaran ini terdapat kesamaan dan perbedaan. Kesamaan antara lain sama-sama memerlukan tempat pembelajaran di luar ruangan dan bergerak atau berpindah tempat. Perbedaanya outbond berpindah tempat jangka waktu panjang juga untuk memisahkan tahapan demi tahapan, sementara permainan tradisisonal terdapat gerak atau perpindahan tempat dengan tempo cukup cepat dalam waktu singkat.

Menurut Subagiyo, H(hlm.6) menyatakan bahwa permainan tradisional adalah permainan tradisi rakyat suatu daerah, permainan ini menjadi sarana yang baik dalam mengembangkan pendidik anak. Untuk mempertahan budaya nasional, melalui pembelajaran outbond berbasis permainan tradisional sangatb membantu dalam pembelajaran karena melingkupi hamper semua pelajaran.

F. Paduan Pembelajaran Berbasis STEM Dengan Pembelajaran Outbond Berbasis Permainan Tradisional Yang Diimplementasikan Di Outdoor

Memadukan pembejaran berbasis

STEM dengan pembelajaran outbond berbasis permainan tradional yang diimplemetasikan di outdoor adalah perpaduan demi tercapainya keoptimalan belajar. Sehingga dapat meningkatkan nilai pendidikan.

"Materi, proses, dan fungsi permainan tradisional juga merupakan media yang tepat untuk belajar, karena dapat bermain dengan ceria, setelah permainan usai tanpa disadari ada pengetahuan yang didapat, juga memberikan pendidikan lingkungan 
sekitar serta menghormati sesame"(Subagiyo, H. hlm.6).

Menurut Permananasari, A (2016, hlm.7) menyatakan bahwa penerapan STEM dalam Pembelajaran dapat mendorong peserta didik untuk mendesain, mengembangkan dan memanfaatkan teknologi, mengasah kognitif, manipulative, afektif, serta mengaplikasikan pengetahuan.

\section{SIMPULAN}

Pembelajaran STEM berbasis outbound permainan tradisional merupakan upaya yang dapat diterapkan di Sekolah Dasar untuk mewujudkan generasi yang memahami akan tekonogi dan menciptakan teknologi baru. Karena di pembelajaran ini akan menghasilkan suatu karya dalam suatu pertemuan, sehingga dapat meningkatnkan semangat peserta didik untuk belajar dan mampu bersain dengan pendidikan negara maju. Kekayaan Indonesia harus dimanfaatkan dari muali permainan tradisional, alam yang memiliki manfaat yang banyak. Begitu pula dengan Sumber Daya Manusia yang memiliki potensi kecerdasan dan kesantunan untuk menjadi bangsa yang sejahtera.

\section{DAFTAR PUSTAKA}

Fitri, F.2016. Pengembangan Buku Panduan Outbond IPA bagi Pendidik Bidang Kajian Materi Dan Sifatnya Pdf. UIN Sunan Kalijaga Yogyakarta

Falah, N. 2014. Efektifitas Outbond Sebagai Metode Pembelajaran. UIN Sunan Kalijaga Yogyakarta.
Ilham, dkk. 2016. Pemanfaatan Permainan Tradisional Dalam Pencapaian Indikator Pembelajaran. Universitas Jambi

Ja'far, A, dkk. Penciptaan Buku Ilustrasi Permainan Tradisonal Sebagai UpayaPelestarian Warisan Budaya Lokal. STMIK STIKOM Surabaya Modul4. Permainan tradisional 1. Permainan anak dan aktivitas ritmik

Permananasari, A. 2016. STEM Education: Inovasi Dalam Pembelajaran Sains.Universitas Pendidikan Indonesia.

Setyowati, I. 2011. Aktivitas Belajar Siswa dalam Pembelajaran Outdoor Study Pada Mata Pelajaran IPS. Universitas Negeri Semarang.

Utami, IS, dkk. 2017. Pengembangan STEMA (Science, Technology,Engineering, Mathematic and Animation) Berbasis Kearifan Local dalam Pembelajaran Fisika.Jurnal Ilmiah Pendidikan Fisika.

Subagiyo, H. Permainan Tradisonal sebagai Media Pembelajaran Anak. Wulandari, Y. 2013. Pengembangan Permainan Outbond Untuk Mendorong Peningkatan Keterampilan Gerak Dasar Siswa Paud Hiodayatullah. Universitas Negeri Semarang. 